Conversely, in my experience, general medical practitioners (GMPs) consistently refer patients to our team via telephone call directly. This allows us to make an informed decision regarding patient care and does not compromise safety or efficiency.

Is the difference between GMPs and GDPs due to differences in teaching on referring patients? Or due to GMPs' increased experience in referring patients? Either way, professional courtesy would suggest that all referrals should be via telephone call from the referring practitioner to the accepting clinician, not via a non-clinical intermediary.

H. Pugh, Chelmsford, UK DOI: 10.1038/s41415-019-0478-1:

\section{Green dentistry}

\section{The BDJ polywrap}

Sir, could I request that the $B D J$ gives consideration to replacing the polythene packaging used to send the journal? The National Trust now send their magazine to members proudly emblazoned with the information: 'I AM 100\% COMPOSTABLE AND CONTAIN POTATO STARCH'

There would also be an opportunity to use this material to comply with HTM 01-05 and other legislation which introduced sealable pouches for most dental instruments. Assuming 10,000 dentists use, say, 20 pouches a day, there will be in excess of four million plastic sleeves, headrest covers and instrument pouches (most have plastic windows) to be disposed of annually.

\section{R. Baker, Cardiff, UK}

\section{The Editor-in-Chief replies: thank you for} your letter which reflects several that we have received in recent times on this subject. Springer Nature, who publish the BDJ and the other BDJ Portfolio publications on behalf of the owners, the BDA, have strong and continually reviewed and updated environmental policies which are reflected across the Portfolio. This includes the use of acid-free, recyclable paper and the use of recyclable plastic wrapping. As indicated on the wrapper itself, together with the recyclable logo, the film can be included with, for example, plastic supermarket bags in appropriate recycling bins and we know that readers do undertake this.

We continually review the materials we use and have researched oxodegradeable film, biodegradable film and compostable film (manufactured from potato starch or corn starch - as mentioned by our correspondents).
Currently the latter are not the same cost as recyclable plastic but are between five and six times more expensive. Industry intelligence suggests that these prices are likely to fall in future and we will continue to monitor this in the delicate balance between costs and environmental considerations.

\section{DOI: 10.1038/s41415-019-0477-2}

\section{LGBT+ recognition}

\section{Lack of understanding}

Sir, I was very disappointed to read

$S$. Worthington's letter in the recent issue of the $B D J .{ }^{1}$ I feel it shows a lack of understanding of the purpose of the rainbow lanyard. The purpose is to encourage inclusivity and help to break down barriers that some LGBT+ people feel in talking freely to health professionals. Use of the lanyard is not designed to be a political statement. As such it supports GDC Standards 2013 section 1.6.1: You must not discriminate against patients on the grounds of age, disability, gender reassignment, marriage and civil partnership pregnancy or maternity, race religion or belief, sex, or sexual orientation. It provides reassurance to LGBT+ staff and patients in the NHS that they will not be discriminated against.

If a lanyard were introduced to reassure staff and patients that they would not be discriminated against on the basis of race, I wonder if the writer would also refuse to where this on the grounds that it may cause distress to those who hold racist views?

L. Nichols, New Malden, UK

\section{References}

1. Worthington $S$. Why I refuse the rainbow lanyard. $\mathrm{Br}$ Dent J 2019; 226: 635-636.

DOI:

\section{Oral health}

\section{'Natural' toothpastes}

Sir, oral health care is a major concern for the general public and people are happy to spend extra dollars on oral hygiene. Toothpaste is a major consumer product for oral health and is used by all of us regularly.

However, there is a debate between fluoride and non-fluoride toothpaste with the market for fluoride-free toothpaste growing quickly., A friend recently asked me an interesting question, being a consumer of natural toothpaste: 'why are natural toothpastes more expensive than fluoride based ones?'
I researched the market prices of natural/ organic toothpaste, finding that that prices range from NZ\$4.99-9.99 per $100 \mathrm{~g}$, which is expensive for daily consumption. Further investigation showed that all of them have common ingredients in the formulation such as calcium carbonate, glycerol, menthol, xylitol, sodium bicarbonate, lauryl glucoside, carrageen, essential oils, xanthan gum and stevia, with few minor variances. As an experienced pharmacist and researcher, I decided to formulate my own natural toothpaste using the same ingredients to evaluate costing. This formulated toothpaste was around NZ\$1.50 (0.76 GBP) per $100 \mathrm{~g}$ including packaging cost. Considering a 50\% profit margin for the company with other expenses, the product price should stay at $\mathrm{NZ} \$ 3.00$ (1.50 GBP) per $100 \mathrm{~g}$.

In summary, the purpose was not only to save a few dollars per tube but also to make dental professionals aware of the ridiculously high profit margins on natural oral care products of this type, so that they can pass on this useful information.

K. Patel, Auckland, New Zealand

\section{References}

1. McKay A. Organic toothpaste. Br Dent J 2012; 212: 206

2. Bartlett D, Smith B, Wilson R. Comparison of the effect of fluoride and non-fluoride toothpaste on tooth wear in vitro and the influence of enamel fluoride concentration and hardness of enamel. Br Dent J 1994; 176: 346.

DOI: 10.1038/s41415-019-0475-4

\section{Oral health education}

\section{Inconsistent approach in schools}

Sir, it is disappointing to see the UK rank bottom in a global survey of oral health education in schools. Sadly, our experience indicates there is an inconsistent approach in schools to delivering oral health education and children are rarely taught about how to look after their own teeth. This is a serious missed opportunity to influence a child at an influential stage of their life. Teachers have told us they lack the knowledge and confidence to talk about the key oral health messages, and oral health does not feature prominently in key stages one and two of the national curriculum. As this survey reveals, we are falling behind in the global league table with many developing countries outperforming the UK.

This is something we have been aware of in Plymouth, UK, where schools have requested more support in delivering oral health education. In response, we have developed a 